\title{
Exhumando la «cultura de catacumbas»: el desarrollo de la ciencia histórica en el Consejo Nacional de Investigaciones Científicas y Técnicas (CONICET) durante el «Proceso de Reorganización Nacional» $(1976-1983)^{1}$
}

\section{Exhuming the «culture of catacombs»: the development of historical science in the CONICET during the «National Reorganization Process» (1976-1983)}

Agustín Rojas ${ }^{2}$

Resumen:

En este trabajo se pone en relieve las principales políticas científicas impulsadas por $\mathrm{CO}$ NICET en cuanto al desarrollo de la ciencia histórica durante la última dictadura militar. Concentrándose en los agentes intervinientes y sus políticas implementadas, se evalúa el impacto de las mismas a lo largo de la última dictadura cívico-militar y luego tras la recuperación democrática, observando ambigüedades, continuidades y rupturas.

Palabras clave: ciencia; dictadura; CONICET; conservadurismo

\section{Abstract:}

This work highlights the main scientific policies promoted by CONICET regarding the development of historical science during the last military dictatorship. Focusing on the intervening agents and their implemented policies, their impact is evaluated throughout the last civic-military dictatorship and after the democratic recovery, observing ambiguities, continuities and ruptures.

Keywords: science; dictatorship; CONICET; conservatism

\footnotetext{
${ }^{1}$ Trabajo recibido el 02/08/2020. Aceptado el 19/10/2020.

${ }^{2}$ Universidad Nacional de Córdoba. Contacto: rojasagustin033@gmail.com
} 


\section{Introducción}

En este artículo se examinará un objeto de estudio en constante expansión: la relación entre la ciencia histórica y el autoritarismo en Argentina. Constituye un trabajo preliminar de una investigación en curso. Ateniéndose a la última dictadura cívico-militar, autodenominada «Proceso de Reorganización Nacional» (1976-1983), se han desprendido diversas problematizaciones en cuanto al desarrollo científico en diferentes escenarios institucionales (Sábato, 1996; Álvarez, 2006; García Moral, 2010; Goebels, 2013; Gárgano, 2015; Fares 2017; Rodríguez 2017). Estudios pioneros de las últimas décadas, al recorrer los vínculos entre los cambiantes climas políticos y los elencos historiográficos, revelaron la tensa disputa por el control de los recursos públicos entre los productores culturales durante el siglo XX (Quattrocchi-Woisson, 1995; Sigal, 2002; Devoto y Pagano, 2009). Una madura historia de los intelectuales implica acercarse a una historia de las culturas políticas con el fin de observar su incidencia en la disputa por las significaciones y el rol del Estado (Altamirano, 2013).

Este trabajo se propone explorar las prácticas científicas de los historiadores en la última dictadura considerando los estudios parciales y detectando déficits interpretativos tales como las representaciones monolíticas del período. El golpe de Estado de 1955, protagonizado por la «Revolución Libertadora», había asumido la función pública prometiendo la «desperonización» de la cultura. La fracturación de la sociedad durante la experiencia democrática encarada por las presidencias de Juan Domingo Perón (1946-1955), cobró un viraje tal que colaboró en afianzar identidades construidas como antagónicas. Luego de lesionarse gravemente el sistema político, se desplegó cierta «purificación» delos espacios públicos para liberar el acceso a las fuerzas «vencedoras» sin imponerse, sin embargo, una hegemonía (Cavarozzi, 1987, p. 24). Los intelectuales antiperonistas intervinientes pertenecían a fuerzas heterogéneas. María Estela Spinelli (2005) destaca «su identificación genérica con valores socioculturales y políticos de una pretendida tradición republicana y el rechazo de la cultura popular del peronismo, como la negación o la antítesis de ésta» (p.14).

Producto de la crisis de dominación la radicalización de la sociedad argentina entre 1969 y 1976 aglutinó a muchos de estos agentes en diferentes fuerzas políticas. El Consejo Nacional de Investigaciones Científicas y Técnicas no fue precisamente ajeno al fluctuante cambio institu- 
cional. El desarrollo de la ciencia histórica durante el último gobierno cívico-militar continúa siendo un territorio en permanente exploración. Una fuerza política autoritaria dispuesta a refundar la república ungiéndola bajo la tradición «cristiana y occidental», donde las proclamas de liberales conservadores tales como Ricardo Zinn reverberaban legitimando al régimen, no pudo prescindir de la historia. Por lo que resulta conveniente plantear interrogantes como los siguientes: ¿Qué políticas de la historia impartieron las Fuerzas Armadas? ¿Qué función políticacientífica llevó a cabo el CONICET en este escenario? ¿Cuáles fueron los elencos historiográficos favorecidos y qué rol ocuparon durante la transición democrática?

\section{La ciencia histórica bajo el autoritarismo y la democracia}

Tulio Halperín Donghi (1986) ha identificado durante el posperonismo lo que concebía como una «crisis historiográfica» producto no solo de la inestabilidad institucional, sino del revisionismo histórico combatiente contra la denominada «historia oficial» y la herencia metódica de la «Nueva Escuela Histórica», es decir, elencos tradicionales asociados a la clásica práctica erudita-documental. Gracias a la primacía de ambas corrientes intelectuales las posibilidades de una verdadera renovación historiográfica terminarían siendo precarias. En palabras del eminente historiador: «por treinta años la historiografía argentina iba a vivir una suerte de crisis permanente, bajo el impacto de ese abrumador punto de partida ofrecido por la obra de Mitre, que parecía tan imposible de continuar como de dejar de lado» (p.489).

Dentro de los aspectos luminosos la educación pública entre la década del '60 y principios del '70 gozó de un presupuesto en ascenso (Buchbinder, 2005, p.178). Puede destacarse, al respecto, la atención al campo científico asignándole el Estado recursos para su actualización y ampliación, lo cual ingresaría en absoluta contradicción con las asonadas conservadoras a partir de la «Revolución Argentina»(1966-1973), destruyéndose parte de los impulsos iniciales. Además de la creación sin precedentes de universidades públicas y privadas, el Estado avanzó proveyendo una arquitectura financiera para las políticas culturales mediante la creación del Fondo Nacional de Artes (FNA) y el Consejo Nacional de Investigaciones Científicas y Técnicas (CONICET). El mapa universitario había sido extendido gracias al Plan Taquini, que implicó llegar en 
1970 al umbral de veintitrés universidades nacionales ubicadas en las provincias. El despliegue de este Plan sin duda había resultado como consecuencia de los estallidos sociales en los principales centros urbanos durante la «Revolución Argentina» y también como respuesta al fuerte crecimiento de la matrícula. Al descentralizar las universidades dispersando el cuerpo estudiantil en las áreas interioranas se presumía disminuir sobre todo la conflictividad latente.

El Consejo Nacional de Investigaciones Técnicas y Científicas (CONITYC) creado por el primer peronismo y refundado por la «Revolución Libertadora» como CONICET, siendo su director el emblemático Bernardo Hussay hasta su fallecimiento en 1971, encontró un período de despegue en los años '60. Las ciencias humanas tardíamente obtuvieron mejoras cualitativas. Aunque cientistas sociales pudieron financiar sus trayectorias, como el caso de G. Germani, la Comisión Directora en Ciencias antropológicas, arqueológicas e históricas (COASAC) había quedado subordinada desde la «Revolución Argentina» bajo agentes conservadores (Rodríguez, 2016). Tal como procedieron T. Halperín Donghi, Carlos Assadourian y Sergio Bagú desde 1966, se sumarían al éxodo otros historiadores de izquierdas como José C. Chiaramonte, Alberto J. Pla, Guillermo Beato y Aníbal Arcondo, instalándose en México.

La radicalización política en la década del '70 había polarizado los arcos ideológicos. El golpe de Estado, ejecutado el 24 de marzo de 1976, acrecentó automáticamente las purgas, despidos y exilios entre los docentes universitarios e investigadores. El gobierno cívico-militar emergente se sustentó sobre un régimen de disciplinamiento, con una inicial legitimidad, asumiendo entonces la misión de «higiene social» (González Bombal, 2004). La «crisis nacional» era responsabilidad de las acciones desmesuradas de la democracia de masas, según el balance propinado por la Junta Militar, optando entonces por la eliminación de la participación política. Los intelectuales y académicos antiperonistas cesanteados de sus cargos como docentes e investigadores universitarios, durante el tercer gobierno peronista, retornaron a sus cátedras e institutos de investigación apoyando en muchos casos al nuevo gobierno.

La simplificación del campo político significó un territorio hostil para aquellas modalidades historiográficas cuyo eje articulador había sido principalmente la instrumentalización de la historia para la praxis política. El nuevo perfil autoritario y tecnocrático estaba interesado en escasos gestos de «revisión historiográfica», pues consideraba que las banderas impugnadoras del revisionismo habían contribuido sólo en exacer- 
bar las confusiones (Álvarez, 2006). En tal sentido, el relato romántico decimonónico recuperaba protagonismo convergiendo con expresiones nacionalistas vinculadas a las preocupaciones políticas del siglo XX. La comunidad nativa era concebida en términos esencialistas o «espirituales», frente a amenazas exógenas adulteradoras del «Ser nacional». Esta situación no había implicado que el gobierno militar anulara sus simpatías por algunas vertientes revisionistas. Simplemente se promovieron políticas culturales dentro de una poética del saber que brindara garantías de un pacto individualista basado en el no cuestionamiento hacia el régimen de verdad estatal. La suspensión del Estado de Derecho había modificado la fisonomía de los escenarios intelectuales: las instituciones de enseñanza, las polémicas posibles, los registros culturales, la circulación y recepción de bibliografía, cualquier disposición de recursos humanos, quedaron drásticamente limitados bajo el control de ciertos productores culturales antorizados (Ivernizzi y Gociol, 2002, pp.22-30). Debido a los altos riesgos y hermetismos culturales se produjeron inevitables anquilosamientos en correlación a los estándares internacionales. Los resultados científicos producidos durante esta etapa fueron, sin embargo, mucho más complejos y con un grado de diversificación que matiza en cierto modo la imagen «oscurantista» que impregna a la totalidad de los productores culturales asumiéndolos homogéneamente (Pagano, 2004, p.159).

Los mecanismos utilizados por el Ministerio de Cultura y Educación eran llevados a cabo a menudo por ciudadanos civiles, la mayoría de ellos católicos, que fijaban criterios y bases normativas (Álvarez, 2006 y Gudelvicius, 2012). El perfil antipartidario incitaba la incorporación de «técnicos», pero también figuras morales adecuadas para la función pública. Llamativamente, algunos de estos agentes ya habían participado con distintos rangos y funciones durante la «Revolución Argentina». Cabe señalar que, antes de 1976, se habían fundado numerosos institutos de investigación privada. Tal fue el caso del historiador católico Ricardo Zorraquín Becú -embajador en Perú durante el anterior administración castrense-, expulsado de la Universidad de Buenos Aires tras ser calificado como «dependiente cultural», creando entonces el «Instituto de Investigaciones en Historia del Derecho» con la colaboración de sus discípulos José María Mariluz Urquijo y Víctor Tau Anzoátegui, recibiendo financiamiento de CONICET desde 1976 (Fernández Koke y Piedra Lertora, 2013, p.202). Esta sociabilidad intelectual se identificaba bajo la «Escuela Jurídica de Levene» investigando la historia colonial desde el 
iusnaturalismo. El liberal antiperonista Ricardo Caillet Bois, asimismo, regresó al Instituto de Historia Argentina y Americana «Dr. Emilio Ravignani» en 1976. Tras su fallecimiento en 1977 fue sucedido por la historiadora del Derecho y esposa del mencionado J.M. Mariluz Urquijo, Daisy Rípodas Ardanaz. Los institutos de investigación en general pasaron a la órbita de los herederos de la «Nueva Escuela Histórica».

La mayoría de los historiadores beneficiados por la coyuntura pertenecían o eran próximos a los miembros vitalicios de la Academia Nacional de la Historia e instituciones tradicionalistas afines como las juntas provinciales de historia. Estos intelectuales lograron sortear los conflictos de esta etapa beneficiándose de una mejora presupuestaria visible en nuevas publicaciones y el sostenimiento de congresos de gran envergadura. El alto endeudamiento con organismos internacionales incluía obligaciones a la Junta Militar de financiar la ciencia y la cultura. Una investigación relevante de Fabiana Bekerman (2015) demostró que el CONICET había presenciado una evolución vertiginosa de su presupuesto. La autora ha registrado que, entre los investigadores desaparecidos, seiscientos ochenta trabajadores despedidos y la merma cultural, hubo muchos científicos que iniciaron sus trayectorias e institutos de investigación creados en áreas interioranas. Formaba parte de una política de descentralización y «crecimiento desproporcionado». El personal de apoyo gozó de un aumento del 231\% y los becarios un 506\%, en 1982, con respecto al personal de 1976 (Bekerman, 2015, p.160). Constituyó, pues, uno de los claroscuros del período.

\section{Estrategias de los investigadores durante la coyuntura autoritaria}

La «cultura de las catacumbas», en palabras de Hilda Sábato (1996, p. 29), ofreció espacios sociales desalentadores para las ciencias sociales con sus respectivas actualizaciones paradigmáticas, arrojando a muchos agentes a la investigación fuera de las universidades. Un ejemplo que quizá colabore en visibilizar la vitalidad productiva de los espacios privados durante la dictadura fue la creación del Programa de Estudios de Histórica Económica y Social Americana (PEHESA), en 1977, el cual a su vez formaba parte del Centro de Investigaciones Sociales sobre el Estado y la Administración (CISEA). Allí Hilda Sábato, Luis Alberto Romero y Leandro Gutiérrez participaban de proyectos historiográficos bajo diseños modernistas abarcando estudios de la cultura popular y los 
orígenes del desarrollo capitalista argentino. Pese a no contar con el apoyo del CONICET, la Fundación Ford financió tales proyectos e, incluso, una estadía en Londres para el caso de Sábato.

Pero significar únicamente 1976 como bisagra ignora, o invisibiliza parcialmente, que tanto el CONICET como las universidades nacionales habían estado intervenidas regularmente desde décadas atrás, con una autonomía precaria. Las renuncias o purgas sucesivas de 1974 y 1975 habían desalojado a muchos investigadores previamente. En vísperas del golpe de Estado de 1976, la Secretaría de Inteligencia del Estado podía diferenciar las opciones políticas en el cuerpo de científicos. El CONICET, vulnerable al poder político, comenzó a contar con interventores afines a las políticas oficiales. El florecimiento de centros privados fue una de las tantas respuestas a estas políticas (Pagano, 2004, p.160). Muchas de las iniciativas como la descentralización y el apoyo de áreas científicas consideradas marginales eran de larga data, solo que manifestaron un auge notorio. Al respecto, la investigadora Adriana Feld (2015) es contundente al afirmar que, entre 1976 y 1981, el principal organismo de promoción científica del país aumentó a más de cien la cantidad de institutos con su consecuente planta de investigadores ingresantes a la carrera.

Los miembros del Directorio poseían la capacidad de administrar los subsidios, con un pico máximo en 1981, sin más controles que las negociaciones privadas pactadas entre estas mismas élites anticomunistas. Durante la dictadura el genetista Sol L. Rabasa, entonces Secretario de Ciencia y Técnica, denunció sin éxito la capitalización de las fundaciones, pues pese a ser un funcionario no menor el poder político de ciertos investigadores era evidentemente enorme. Como prueba de ello, la Fundación para la Educación, la Ciencia y la Cultura (FECIC) en 1982 solicitó al Ministerio de Educación y Cultura la entrega de una finca que debía ser destinada al Instituto de Historia y Antropología Hispanoamericana alegando el siguiente justificativo:

(...) es necesario formar recursos humanos, en áreas de la ciencia que han estado en estos años y aún lo están muy politizadas, especialmente bajo la Influencia marxista-leninista como la de Antropología (Arqueología, Etnología, Antropología Social, Folklore Científico, Indigenismo) (...) Otras disciplinas que fueron muy penetradas por ese accionar político disolvente fueron las licenciaturas en Sociología y Psicología. (...) Por ello si hay que formar jóvenes licenciados en Antropología, Historia y Arte en el campo de la cien- 
cia y la tecnología del país y becarios hispanoamericanos, es fundamental realizarlo por medio de planes de investigación concretos, tanto de campo como de gabinete con un profundo sentido americanista asentado en las raíces de la cultura occidental y cristiana. ${ }^{3}$

En este sentido, se aplicó una política de incentivos desde 1977 privilegiando a las áreas interioranas. ${ }^{4}$ Lo cierto es que no todos los investigadores se dejaron absorber por fundaciones fraudulentas tales como FECIC, SENOC u OIKOS. Sin abandonar el anclaje laboral en las universidades, los principales elencos historiográficos que canalizaron estos recursosdes de institutos o centros preexistentes fueron: a) la Escuela Histórica de la Plata; b) la Escuela Jurídica de Levene en Buenos Aires; b) la Escuela Sevillana en la Universidad Nacional de Cuyo; y c) otros equipos interdisciplinares del Interior dialogando con la geografía, arqueología y antropología, nucleados en la Universidad Nacional del Nordeste, la Universidad Nacional de Córdoba y la Universidad Nacional de Catamarca. Dichos investigadores distaban de ser homogéneos, puesto que se auto adscribían en el complejo arco ideológico desde el demoliberalismo hasta el republicanismo conservador antidemocrático (Fares, 2017). Asimismo, el impacto historiográfico de tales proyectos resultó disímil. Entre las predilecciones temáticas sobresalían unas renovadas historias regional y económica-social conviviendo aún, sin embargo, con la historia política tradicional. La matriz humanista de la Historia argentina y americana seguía en pie financiada por numerosos programas de apoyo.

Otros historiadores favorecidos, ligados a las universidades confesionales católicas, fueron aquellos vinculados a la Fundación Nuestra Historia, institución revisionista ligada al Instituto Bibliográfico «Antonio Zinny» (García Moral, 2010, p.84). Bajo la dirección de Jorge C. Bohdziewich, esta institución comenzó a contar con apoyos de CONICET y estaba conformada por hispanistas como Ernesto Maeder, Vicente Sierra, Roberto Marfany, Edberto Acevedo, Pedro Santos Martínez. Otro presupuesto otorgado por la Secretaria de Cultura se obtuvo gracias a la consulta efectuada por el Ministro Amadeo Llerena a la Academia Nacional de la Historia en 1976, donde muchos de estos historiadores formaban parte paradójicamente (Barba, 1977, p.35). También el

${ }^{3}$ Informe sobre los hechos ocurridos en el CONICET entre 1976 y 1983 (1989, p. 33). ${ }^{4} \mathrm{Al}$ respecto, consultar Informe sobre los hechos ocurridos en el CONICET entre 1976 y 1983 (1989) y Rodríguez (2015). 
mismo funcionario pidió asesoramiento de la corporación en 1977 para redactar un preproyecto de Ley Nacional de Educación no ejecutado.

Desde 1976 hasta la intervención del CONICET en 1984 se destacaron numerosos historiadores conservadores que lograron ocupar las comisiones regionales y asesoras hasta acceder a la Junta de Calificaciones en calidad de Investigadores Superiores. José María Mariluz Urquijo(1921-2018) fue designado por Jorge Rafael Videla y el Ministro de Educación y Cultura Llerena Amadeo en el Directorio de la misma manera que el sociólogo tomista Roberto Brie (1926-2003), ambos presentes en el organismo desde la «Revolución Argentina» (Rodríguez, 2017). Estas figuras mantenían vínculos fluidos con los diversos historiadores del organismo científico apoyando sus iniciativas como el caso de Horacio Cuccorese (1921-1990), integrante de la Junta de Calificaciones y la Revista Nacional de Cultura financiada por la Secretaría de Cultura. Podrían citarse otros investigadores tales como Pedro Santos Martínez (1925-2008), Jorge Fermín Comadrán Ruiz (1925-2004), Armando Bazán (1925-2019), miembros de una de las Comisiones Regionales en Cuyo, y Víctor Tau Anzoátegui (1933), miembro de la Comisión Asesora por Buenos Aires. Los tres primeros incursionaron en la demografía y la historia económica-social, sin renunciar a la historia política fáctica, y los últimos dos en la Historia del Derecho Indiano vinculándose con la Escuela de Estudios Hispanoamericanos de Sevilla. Sin excepciones, los historiadores mencionados pertenecieron a la Junta de Historia Eclesiástica y estaban insertos en las redes académicas americanistas.

Las ausencias de RircardoZorraquínBecú(1911-2000) y EduardoMartiré (1932) en el CONICET, pese a los beneficios obtenidos gracias a sus conexiones con estas figuras, son explicables debido a sus carreras en el Poder Judicial Federal. Habían logrado materializar, en 1977, el Profesorado en Historia en la Pontificia Universidad Católica de Buenos Aires. E. Martiré fue el director del Departamento de Historia hasta 1985. La propuesta curricular argumentaba «defender nuestra identidad nacional, indisolublemente ligada a nuestra fe» (Hubeñak, 2016, p.72). Estos movimientos formaban parte de sectores protagónicos respondiendo a las matrices ideológicas de las élites conservadoras. Sin embargo, insistir en la homogeneidad ideológica y socioprofesional de los agentes culturales, resulta una tarea que exige acotaciones prudentes. No sería veraz, en efecto, asumir una imagen totalizadora de un escenario ocupado absolutamente por una derecha católica reaccionaria 
sin distinguir los distintos roles ejercidos. En la mayoría de los casos, los científicos activos entre 1974 y 1983 no significaban intromisiones externas sino elementos inherentes favorecidos por la coyuntura. Desarrollaron estrategias adaptativas sin capacidad de negociación con los interventores u optaron, provisoriamente, por legitimar las fuerzas conservadoras renunciando al pacto con las mismas tras el fracaso bélico de 1982, e integrándose no forzosamente a las estructuras científicas posalfonsinistas.

En el CONICET había resultado evidente, en efecto, el deslizamiento de algunos historiadores con una intrépida trayectoria profesional aprovechando el ausentismo forzado de quienes renunciaron entre 1974 y 1976, víctimas del aparato paraestatal. Investigadores jóvenes indemnes por distintas razones -rol de ajenidad frente al clima autoritario, autoprotección para sobrevivir, ocultaban sus inclinaciones políticas, etc.- lograron atravesar el contexto «oscurantista» sin optar por el exilio. Esto no significa que no hayan sido vigilados por las autoridades ni sufrido cesantías dentro de sus equipos. La imagen de un retorno automático a la producción conservadora, protagonizada por la «vieja historia» metódica, anulándose por completo, pues, la diversificación historiográfica emergente, carece de realismo. Los subsidios destinados al área de humanidades en el CONICET lograron acrecentar la cantidad de becarios y garantizar el inicio de sus carreras entre 1979 y 1982.

Efectivamente, luego de la primera etapa de «depuración» le sucedió otra, entre 1979 y 1981, de «seminormalización». El CONICET y sus dependencias, reestructurados en 1981 habiendo asumido como Director el civil Juan Carlos Gottifredi, se transformaron en una meta incluso más atractiva que las universidades. Los flujos principales del financiamiento estatal intentaban evitar las casas de estudios y sus institutos dependientes. Sin embargo, no es conveniente aceptar que hubo un único paradigma tolerado. A modo ilustrativo, H. Cuccorese también fue responsable de la promoción de vertientes de historia económica prolíficas en la década del ' 70 . Con motivo de la recepción en la Academia de su discípula, Noemí Girbal de Blacha, el platense reconocía así las cualidades de la entonces joven candidata para una beca: «Es en ese ambiente de inseguridad social [1966] cuando se nos presenta la joven Girbal para solicitarnos la dirección de una beca de apoyo (...) El año 1978 es fundamental y decisivo en su quehacer investigativo. (...) Girbal de Blacha remontó vuelo para alcanzar la precordillera a que debe subir el investigador»(Cuccorese, 1989, p.145). 
Los paradigmas de las ciencias sociales imponían internacionalmente directrices cada vez más precisas, las cuales exigían modernizar ciertas metodologías y opciones teóricas que trascendían visión humanista heredera de la «Nueva Escuela». La historia «económica-social», o exclusivamente económica, no había sido precisamente monopolizada por los intrépidos grupos renovadores. No deja de ser cierto, de todos modos, que la destrucción de equipos de investigación, la estigmatización del estructuralismo bajo sensibilidades marcartistas, la censura y precariedad editorial, colaboraron en visibilizar el desfasaje entre las prácticas locales y los avances internacionales (Pagano, 2010, p.40). En la Universidad Nacional de La Plata, sin la figura emblemática del ya jubilado Enrique Barba (1909-1988), se destacaron discípulos formados por la vieja guardia de la «Escuela Histórica de La Plata» adquiriendo rasgos innovadores. El caso de Girbal de Blacha es significativo: en 1977 fue Profesora Adjunta interina de la cátedra Historia Argentina del siglo XX, espacio académico y simbólico de trascendencia debido a las tensiones expresadas en el exilio de su titular, José Panettieri. En el mismo año, jerarquizó su trayectoria científica incorporándose en calidad de Investigadora Adjunta, luego de haber gozado de una beca de perfeccionamiento en el mismo CONICET. Sin abrazar opciones interpretativas económicas estructuralistas, sensibles a la cliometría norteamericana o enfoques sociales conflictivistas, concedía un lugar prominente en sus investigaciones a la teoría económica institucional de Douglass North.

Un discípulo de Barba, Samuel Amaral, se había especializado en Estados Unidos regresando al país logrando integrar el plantel platense. Sin duda, una trayectoria similar es la de Carlos Mayo: dirigido en su doctorado por Barba, se formó asimismo en Estados Unidos. Tanto Amaral como Mayo se distanciaron del carácter endogámico platense sumándose a redes académicas internacionales anglosajonas. Fueron beneficiados con becas en sus trayectorias profesionales formándose en el extranjero desde 1970 hasta 1980. Amaral realizó una breve temporada en Stanford University incursionando tras su retorno en el Instituto Torcuato Di Tella. Por su parte, Mayo incurrió su formación en la University of California. Nunca rechazaron el origen platense y su lazo con la Academia Nacional de la Historia. Su acercamiento a revistas internacionales especializadas -como la Hispanic American Histortical Reviewcolaboró, en gran medida, en la recepción de los abordajes teóricos florecientes de los países desarrollados. En el escenario intelectual argentino motivaron agudas polémicas desde Desarrollo Económico. Asimismo, 
otra notable discípula de Barba, Silvia Mallo, también ingresó al CONICET en categoría de asistente desde 1982.

En la Universidad Nacional de Córdoba, se destaca Beatriz Moreyra de Alba, discípula del prominente historiador de la Academia Nacional de la Historia Carlos S. A. Segreti (1929-1998). Iniciaría su carrera en el CONICET bajo la categoría de Investigadora Asistente en 1978, ascendiendo a la categoría de Adjunta en 1981. La joven historiadora sería una de las mayores impulsoras de la historia económica en Córdoba. Al igual que Girbal de Blacha, centraría sus esfuerzos en la historia económica de su provincia, albergando escalas regionales y analizando la evolución de la producción agropecuaria en conjunción con factores institucionales. Otras discípulos de Segreti ingresantes a CONICET fueron Félix Converso, Beatriz Solveira y María Cristina Vera de Flachs. Estaban comprometidos con un enfoque económico y social. Todos ellos se solidarizaron con su mentor tras su cesantía en la Universidad Nacional de Córdoba, ocupando sus cátedras y fundando en 1979 una entidad privada y sin financiamiento de CONICET bautizada Centro de Estudios Históricos. En cuanto a Vera de Flachs, debido a rechazos de sus informes doctorales evaluados por la cordobesa Norma Pavoni, había enviado en 1980 una carta a un Investigador Superior destacado del COASAC, Ernesto Maeder (1931-2015), consultándole la posibilidad de que el informe fuese legitimado:

Por conversaciones con el doctor Berberián [Docente de Prehistoria y arqueología] me enteré que uno de los miembros del Consejo que había informado sobre mi labor era usted (...) Como debo rendir el oral dentro de diez días desearía si usted pudiera enviarme, en forma urgente, su opinión sobre el mismo, ya que además de pertenecer a la Comisión de Historia es un entendido en la materia y reconocido investigador del orden nacional. ${ }^{5}$

Prácticas como la citada sugieren la existencia de mecanismos poco transparentes en cuanto al control de calidad académica. Tanto los jóvenes platenses como cordobeses compartían espacios de sociabilidad intelectual asistiendo a los congresos de la Academia Nacional de la Historia financiados generosamente por la Secretaría de Cultura: el Cuarto Congreso Nacional y Regional de Historia Argentina (1977), Congreso de

${ }^{5}$ Carta de M.C.V.F. a E.J.A.M., Recibida, Caja No5, 30/04/1980, f.01816, FDEJAMIIGHI. 
Historia en Homenaje a la Conquista del Desierto (1979), el Sexto Congreso Internacional de Historia de América (1980) y Quinto Congreso de Historia Nacional y Regional Argentina (1981). Durante el segundo congreso mencionado, Enrique Barba (1980) comparó la «juventud extraviada» de la militancia setentista con los «jóvenes serios» presentes, exhortándolos a una «cruzada para volver a la historia a su curso natural»:

En algún momento una literatura desquiciadora había arrumbado como nefanda de los grandes maestros; el texto fue reemplazado por el panfleto y la lección por la arenga; todo esto en una total claudicación. (...) Al natural zumbido del enjambre, la agitación, como en la colmena, será síntoma del fecundo trabajo que prometen estos jóvenes (p.10).

¿Pueden interpretarse estos direccionamientos como compromisos directos con el régimen? La categoría correcta a utilizar en estos casos es la de adaptación: al tratarse de «jóvenes serios», sin atisbos de peligrosidad civil, estos agentes simplemente aprovecharon recursos a disposición sin por ello apoyar al régimen. Por otra parte, no puede ignorarse que sus trayectorias académicas se perfilaban desde la década del '60 independientemente de las mutaciones políticas. Pertenecían a filiaciones partidarias como el radicalismo y el peronismo. No debe extrañar el hecho de que en 1983 aceptaran con entusiasmo el pacto democrático alfonsinista. Tampoco se encuentra evidencia de una participación explícita en los rituales de legitimación, así como tampoco se destacaron entre quienes firmaron solicitadas en la prensa avalando la dictadura como sí había ocurrido con otros intelectuales. Un aspecto que merece destacarse, problematiza la cuestión del género en cuanto a las posibilidades de ejercer un habitus científico. No es mera casualidad que las discípulas de C. Segreti, H. Cuccorese y E. Barba, B. Moreyra, N. Girbal de Blacha y S. Mallo respectivamente, no hayan desarrollado instancias formativas en el exterior. En este escenario, particularmente resultaba «inapropiado» que las mujeres viajaran solas y debían cargar con la educación de sus hijos además de los deberes científicos. Por otro lado, dentro de la Academia fueron testigos de actitudes misóginas explícitas e implícitas, como la negativa del académico Isidoro J. Ruiz Moreno a la inclusión de mujeres como miembros de número

Una situación similar se observa entre los historiadores que operaban desde el Instituto Torcuato Di Tella. Estos agentes dinamizaron 
circuitos editoriales y espacios institucionales ciertamente modernizantes. Las editoriales Paidós y Sudamericana permitieron circular exitosamente sus obras: La República Conservadora (1976) de Ezequiel Gallo y Roberto Cortés Conde, El Orden Conservador (1977) de Natalio Botana y El Progreso Argentino (1979) de R. Cortés Conde. Algunas de estas obras recibieron la colaboración de algunos miembros de la Academia Nacional de la Historia. El impacto modernizador de estas interpretaciones se había desarrollado con éxito bajo el paradigma liberal clásico, lo cual les garantizaba cierta inmunidad ante la censura. Producto de la sociabilidad intelectual entre estos agentes con los bordes más modernizantes de la Academia en los años finales de la dictadura, se fundaría la Asociación Argentina de Historia Económica con el propósito de modernizar metodológicamente las prácticas.

Otros agentes, en cambio, evidenciaron un colaboracionismo con el régimen. Maeder experimentó el período 1976-1983 con intensidad política y científica. Uno de los logros más redituables para su carrera profesional fue, indudablemente, haber formado parte de la creación del Instituto de Investigaciones Geohistóricas (IIGHI) en Corrientes en 1979 (Maeder, 2012). En un comienzo los científicos que llevaban a cabo el proyecto interdisciplinar fueron Alfredo Bolsi, Enrique Bruniard, Norma Meitchtry, Julio César Espíndola y Héctor Borrini. Durante el conflicto territorial con Chile, Maeder integró en 1978 el simposio La Conciencia Territorial, organizado por la fundación OIKOS, analizando la formación fronteriza de la región del Nordeste (Maeder, 1981, pp.147153). El IIGHI dependía del CONICET pero, tanto su financiamiento como su administración, recaían en la entidad privada sin fines de lucro llamada Fundación para el Desarrollo del Nordeste (FUNDANORD). ${ }^{6}$ Siendo Ministro de Educación de Chaco, Maeder gestionó la obtención de dos hectáreas de tierras estatales con el fin de la construcción de una nueva cede del IIGHI en Resistencia a través de la Ley 2509 en 1981

\footnotetext{
${ }^{6}$ FUNDANORD (1977) nació, originalmente, con aportes de sus integrantes sumando una partida de CONICET de \$25.000.000 anticipadamente a la aprobación de su personería jurídica el 04/08/77. FUNDANORD se reservó la administración de esos fondos asignados preservando el valor del mismo, dado el contexto inflacionario, gracias a la renta financiera solventando así nuevos gastos. Las instalaciones, efectivamente, se hicieron fortaleciendo la cohesión científica de los institutos del Nordeste. Aunque luego Maeder se alejaría de dicha fundación, no se pudo comprobar, a diferencia de otras fundaciones como SENOC, un enriquecimiento corrupto sino sólo una situación privilegiada. Informe sobre los hechos ocurridos en el CONICET entre 1976 y 1983 (1989, pp.28-29).
} 
(Maeder, 2012, p. 247). No obstante, sufrió presiones por parte de las autoridades militares para comprometerlo con la función pública impugnándole en CONICET su nombramiento de Investigador Principal en 1979. Con respecto al impacto modernizador del IIGHI, es imposible eludirlo teniendo en cuenta la precaria profesionalización del Nordeste. No en vano, Haperín Donghi (1986) lo destacó entre los proyectos de mayor calidad del período.

En la Universidad Nacional de Cuyo el preexistente Centro de Estudios Interdisciplinarios de Fronteras Argentinas (CEIFAR), coordinado por investigadores de CONICET procesistas como J. Comadrán Ruiz, organizó conferencias avalando la soberanía argentina de la Patagonia durante el efervescente clima «antichileno» (Lacoste, 2003). En su revista Cuadernos se pude apreciar la predilección hacia el estudio interdisciplinar entre geógrafos, geólogos e historiadores de la región. Estos académicos lograron asesorar al gobierno ampliando el ejido provincial. La mayor dotación presupuestaria se llevó a cabo durante la gestión de Santos Martínez, rector de dicha universidad en el período entre 1976 y 1981. En la misma casa de estudios, el historiador-jurista Dardo Pérez Guilhou -Ministro de Educación durante el gobierno de Carlos Onganía- había fundado el Instituto Argentino de Estudios Constitucionales y Políticos (1981), dirigiendo a un grupo de becarios explorando la historia del Derecho.

En la Universidad Nacional de Catamarca, A. Bazán -ingresado a CONICET en 1979- había creado el Centro de Investigaciones Históricas del Noroeste Argentino (1983) casi en el término del «Proceso». El estudio de la región del Noroeste conservaba una significación análoga a la propuesta interdisciplinar de Maeder y Comadrán Ruiz: una demarcación cultural y geográfica transhistórica, enfatizando en las continuidades y cambios, participando mancomunadamente historiadores, geógrafos y antropólogos (Bazán, 1986). Estos investigadores apoyaron al gobierno durante la Guerra de Malvinas, más allá de criticar privadamente el uso demagógico del conflicto, brindando conferencias y produciendo abundante material. La insistencia en afirmar que las islas correspondían al Estado nacional argentino en tanto fueron parte del ejido virreinal, integraban la plataforma continental y figuraban en la toponimia, condensaron los consensos interpretativos vitales. 


\section{Conclusiones}

Tradicionalmente la ciencia en el período dictatorial ha sido significada como «cultura de las catacumbas» enfatizándose, pues, el carácter reaccionario en algunos los operadores culturales, la censura, la represión y el acentuado «medievalismo intelectual». Ahora bien, aunque esta imagen está lejos de ser inexacta deja de lado numerosos aspectos pobremente tratados como: 1) la persistencia de líneas de investigación científica no arcaizantes; 2) el auge presupuestario en el área científica asignado en este período; y 3) la formación de recursos humanos idóneos según los paradigmas internacionales y, algunos de ellos, con inclinaciones democráticas.

En este artículo se intentó llenar estos vacíos ofreciendo una perspectiva más plural de los estudios históricos y los historiadores que entonces competían en el escalafón de CONICET. El diagnóstico ofrecido por Pagano (2010) corresponde a la realidad al afirmar que «al comenzar los años 80 , buena parte del campo historiográfico no se hallaba permeabilizado a las innovaciones, sometido como estaba a un régimen de censuras e interdicciones pero también de atraso autocomplaciente» (p.42). De todos modos, no puede concebirse la reprofesionalización desde una clave absolutamente disruptiva, sin admitir rasgos de una acumulación originaria previa, líneas interpretativas de larga durabilidad y el apoyo de dispositivos institucionales dentro de las élites académicas, muchas de las cuales habían construido un capital nada despreciable. Es decir, una buena parte de los agentes adaptados que convivieron con figuras mediocres durante el «oscurantismo», fueron cómplices de importantes innovaciones.

De cierto modo, la «Nueva Historia» no estalló en 1983/84 sino que dicho paradigma comenzó a convivir con otras corrientes preexistentes de la historia «económico-social» como era llamada. En suma, el paradigma renovador posalfonsinista pudo sostenerse gracias no solo a los cambios institucionales a su favor, sino también al mestizaje entre viejas y nuevas élites académicas compartiendo un campo simbólico e instancias de consagración. En democracia fortalecieron sus trayectorias y consagraciones, sin presenciar las rupturas institucionales como verdaderos obstáculos. Las impugnaciones éticas recayeron especialmente sobre Zorraquín Becú, Santos Martínez, Comadrán Ruiz, Cuccorese y Maeder. Sin embargo, no pudieron ser desalojados del CONICET publicando durante el gobierno de Alfonsín denuncias recopiladas en el 
informe Destrucción de equipos de investigación y persecución de cientificos (1988). Este grupo regresaría al organismo durante el menemismo protegidos por Bazán, miembro entonces del Directorio.

\section{Referencias bibliográficas}

Altamirano, C. (2013) [2006], Intelectuales. Notas de investigación sobre una tribu inquieta. Buenos Aires, Argentina: Siglo XXI

Álvarez, E. (2007). Los intelectuales del 'Proceso'. Una aproximación a la trama intelectual de la última dictadura militar. Politicas de la Memoria, 2006-2007 [Online] file://C:/Users/pc/Downloads/331Texto\%20del\%20art\%C3\%ADculo-644-1-10-20190603.pdf Última consulta: 01/04/2019

Beigel, F. (2018). Reflexiones sobre el uso del concepto de campo y la elasticidad de la autonomía en circuitos académicos periféricos. En Beigel, F. (Dir.). Autonomía y dependencia académica, [Online]. http://nuso.org/media/articles/downloads/3944_l.pdf Última consulta: $05 / 04 / 2019$

Bekerman, F. (2015). El campo científico argentino en los años de plomo: desplazamientos y reorientación de los recursos. Sociohistórica, (26).

Buchbinder, P. (2005). Historia de las universidades argentinas. Buenos Aires, Argentina: Sudamericana.

Cavarozzi, M. (1987). Autoritarismo y democracia. Buenos Aires, Argentina: Eudeba.

Devoto, Fernando (2002), Nacionalismo, fascismo y tradicionalismo en la Argentina moderna. Buenos Aires: Siglo XXI.

Devoto, F. y Pagano, N. (2009). Historia de la historiografía en Argentina. Buenos Aires: Sudamericana.

Fares, M. C. (2017). Las caras del hispanismo: tránsitos y perfiles de intelectuales de derecha en la posguerra. Nuevo Mundo Mundos Nuevos, [Online] http://journals.openedition.org/nuevomundo/ 70537 ; DOI : 10.4000/nuevomundoúltima consulta: 09/08/2019

Feld, A. (2015). Ciencia y dictadura en la SECyT y el Conicet: el modelo de política científico-tecnológica de la Revolución Argentina al Proceso de Reorganización Nacional (1966-1983). En: Gárgano, C. 
(Comp.). Ciencia en dictadura. Buenos Aires, Argentina: INTA. Fernández Koke, D. y Piedra Lertora, F. (2014). Ricardo Zorraquín Becú (1911-2000). Revista Chilena de Historia del Derecho, (24).

García Moral, M. (2010). El revisionismo en los 80 y 90: ‘el anquilosamiento o la convalecencia de una historia militante. En: Devoto, F. (Dir.). Historiadores, ensayistas y gran público. Buenos Aires, Argentina: Biblios

Goebel, M. (2013). La Argentina partida: nacionalismos y politicas de la historia. Buenos Aires, Argentina: Prometeo.

González Bombal, I. (2004). La Figura de la Desaparición en la re-fundación del Estado de Derecho. En: Palermo, V. y Novaro, M. (Comp.). La historia reciente. Argentina en democracia. Buenos Aires, Argentina: Edhasa.

Gudelevicius, M. (2012).La política educativa implementada durante el primer año del 'Proceso de Reorganización Nacional': contradicciones y límites, Trabajos y Comunicaciones, (38).

Halperín Donghi, T. (1986). Un cuarto de siglo de historiografía argentina (1960-1985), Desarrollo Económico, 25 (100).

Hubeñak, F. (2016). Historia de la Universidad Católica Argentina. Buenos Aires, Argentina: UCA.

Invernizzi, H. y Gociol, J. (2002). Un golpe a los libros. Represión a la cultura durante la última dictadura militar. Buenos Aires, Argentina: EUDEBA.

Lacoste, P. (2003). La Academia Nacional de la Historia y el conflicto del Beagle,

Neuquén, Argentina: Consejo Nacional Patagónico.

Pagano, N. (2004). Las ciencias sociales durante la dictadura argentina (1976-1981). En: Devoto, F. y Pagano, N. (Eds.). La historiografía académica y la historiografía militante en Argentina y Uruguay. Buenos Aires, Argentina: Biblos.

Quattrocchi-Woisson, D. (1995 [1989]). Los males de la memoria: historia y politica en la Argentina. Buenos Aires, Argentina: Sudamericana.

Rodríguez, L. (2015). Cultura y dictadura en Argentina (1976-1983), Anuario Colombiano de Historia Social y de la Cultura, 4 (2).

Rodríguez, L. (2017). La derecha en la Universidad: la investigación en 
ciencias sociales. Nuevo Mundo Mundos Nuevos [Online], https:// doi.org/10.4000/nuevomundo.70554 Última consulta: 02/11/2019

Sábato, H. (1996). Sobrevivir en dictadura: las ciencias sociales y la 'universidad de las catacumbas'. En: Quiroga, H. y Tcach, C. (Comps.). A veinte años del golpe con memoria democrática. Rosario, Argentina: Homo Sapiens.

Sigal, S. (2002 [1991]), Intelectuales y poder en Argentina. La década del '60. Buenos Aires, Argentina: Siglo XXI.

Spinelli, M. E. (2005). Los vencedores vencidos. El antipeornismo y la «Revolución Libertadora». Buenos Aires, Argentina: Biblos.

\section{Fuentes:}

Archivo Personal Ernesto J.A.Maeder: correspondencia privada (19581995), Resistencia, IIGHI:Carta de María Cristina Vera de Flachs a E.J.A. Maeder, Recibida, Caja No5, 30/04/1980, f.01816, FDEJAM-IIGHI

Barba, E. M. (1977). Memorias del Presidente de la Academia Nacional de la Historia, Enrique M. Barba, sobre la labor desarrollada en el año 1976, BANH, Vol. XLIX, Buenos Aires: Academia Nacional de la Historia.

Barba, E. M. (1980). Palabras de inauguración del Sr. Presidente de la Academia Nacional de la Historia, Dr. Enrique M. Barba. Congreso Nacional de Historia sobre la Conquista del Desierto, Tomo I, Buenos Aires: Academia Nacional de la Historia

Bazán, A. (1986). Historia del Noroeste Argentino. Buenos Aires, Argentina:Plus Ultra.

Cuccorese, J. H. (1989). Discurso de recepción por el académico de número Dr. Juan Horacio Cuccorese, BANH, Vol. XLII, Buenos Aires: Academia Nacional de la Historia

Girbal de Blacha, N. (1990). Bibliografía del académico de número Doctor Horacio Juan Cuccorese, BAHN, Vol. XLIII, Buenos Aires: Academia Nacional de la Historia

Informe sobre el CONICET durante la dictadura militar (19761983).(1989). Buenos Aires, Argentina: Eudeba

Maeder, E. J.A. (1981). El caso Misiones, su proceso histórico y su posterior distribución territorial. En: Randle, H. Patricio (Ed.). La 
Geografía y la Historia en la identidad nacional, Tomo II. Buenos Aires, Argentina: OIKOS.

Maeder, E. J.A. (2012). El IIGHI. Una aventura institucional compartida: la etapa correntina (1979-1983). En: Maeder, E.J.A. (Coord.). Estudios y contribuciones. Resistencia, Argentina: Con Texto. 